\title{
Independent prognostic genes and mechanism investigation for colon cancer
}

\author{
Chunsheng Li ${ }^{1}$, Zhen Shen ${ }^{1}$, Yangyang Zhou ${ }^{2}$ and Wei Yü ${ }^{1 *}$
}

\begin{abstract}
Propose: We aimed to explore the potential molecular mechanism and independent prognostic genes for colon cancer (CC).

Methods: Microarray datasets GSE17536 and GSE39582 were downloaded from Gene Expression Omnibus. Meanwhile, the whole CC-related dataset were downloaded from The Cancer Genome Atlas (TCGA) database. Differentially expressed mRNA (DEMs) were identified between cancer tissue samples and para-carcinoma tissue samples in TCGA dataset, followed by the KEGG pathway and GO function analyses. Furthermore, the clinical prognostic analysis including overall survival (OS) and disease-free survival (DFS) were performed in all three datasets.
\end{abstract}

Results: A total of 633 up- and 321 down-regulated mRNAs were revealed in TCGA dataset. The up-regulated mRNAs were mainly assembled in functions including extracellular matrix and pathways including Wnt signaling. The downregulated mRNAs were mainly assembled in functions like Digestion and pathways like Drug metabolism. Furthermore, up-regulation of UL16-binding protein 2 (ULBP2) was associated with OS in CC patients. A total of 12 DEMs including Surfactant Associated 2 (SFTA2) were potential DFS prognostic genes in CC patients. Meanwhile, the GRP and Transmembrane Protein 37 (TMEM37) were two outstanding independent DFS prognostic genes in CC.

Conclusions: ULBP2 might be a potential novel OS prognostic biomarker in CC, while GRP and TMEM37 could be served as the independent DFS prognostic genes in CC. Furthermore, functions including extracellular matrix and digestion, as well as pathways including Wnt signaling and drug metabolism might play important roles in the process of CC.

Keywords: Colon cancer, Differentially expressed microRNAs, Function and pathway analysis, Independent prognostic gene, Overall survival, Disease-free survival

\section{Background}

Colon cancer (CC) is one of the best-understood neoplasms from a genetic perspective [1]. Globally, CC is the third most common type of cancer making up about $10 \%$ of all cases [2]. There are over 1.4 million new cases and 694,000 deaths from the CC in 1 year worldwide [3]. Treatments for CC may include some combination of surgery, radiation therapy, chemotherapy and targeted therapy $[4,5]$. Although the integrated surgical strategies increased the survival rate, the removal of the colon may

\footnotetext{
*Correspondence: Warner_Y792@hotmail.com

${ }^{1}$ Gastrointestinal Colorectal and Anal surgery, China-Japan Union Hospital of Jilin University, No. 126 Xiantai Street, Changchun, Jilin 130033, China

Full list of author information is available at the end of the article
}

not suffice as a preventative measure because of the high risk of rectal cancer if the rectum remains [6].

Numerous data indicate that the aberrant accumulation of genetic changes functions as vital roles in initiation and development of colon and rectal cancer [7, 8]. Messenger RNA (mRNAs) are important regulatory molecules which can affect a variety of cellular and molecular targets in various cancers including CC [9]. A previous study shows that different types of mRNA can be used as tissue- and exosome-based diagnostic biomarkers for human CC [10]. The high expression of mRNA such as interleukin- 6 can be used as a predictor of relapse in CC [11]. Furthermore, certain kinds of mRNA can be used to predict survival in CC patients [12]. A previous study shows that Ephrin-A1 mRNA is associated with poor 
prognosis of CC patients based on short disease-free survival (DFS) data [13]. Alexopoulou et al. showed that Kallikrein Related Peptidase 11 mRNA expression could predict poor DSF and overall survival (OS) in colorectal adenocarcinoma patients [14]. Thus, a better knowledge of the molecular mechanisms and cancer associated gene is vital for the early diagnosis and personalized care of $\mathrm{CC}$ patients. However, the independent prognostic gene associated with death and recurrence of $\mathrm{CC}$ is still unclear.

In previous studies, Smith et al. $[15,16]$ and Marisa et al. [17] tried to predict the mRNAs associated with the recurrence and death in $\mathrm{CC}$ patients based on gene expression profiles. Although some valuable biological markers for prognosis of $\mathrm{CC}$ has been revealed, the limited sample size and survival evaluation in these studies are not benefit for the investigation of independent prognostic genes. Based on the previous results from Smith et al. and Marisa et al. The Cancer Genome Atlas (TCGA) dataset associated with CC were added in the current bioinformatics study. By comparing the data between cancer tissue samples and para-carcinoma tissue samples in TCGA dataset, the differentially expressed mRNAs (DEMs) investigation, functional and pathway enrichment analysis were performed. Furthermore, prognostic analysis including overall survival and diseasefree survival rate investigation was performed based on data in all three datasets. We hoped to explore molecular mechanism of $\mathrm{CC}$, and identify candidate independent prognostic genes for CC prognosis.

\section{Methods}

\section{The mRNA microarray data}

Microarray dataset GSE17536 [15, 16] and GSE39582 [17] were downloaded from Gene Expression Omnibus (GEO, http://www.ncbi.nlm.nih.gov/geo/) database. A total of 177 invasive murine CC cells sample were included in dataset GSE17536. Meanwhile, a total of 566 CC samples were included in GSE39582. The gene expression profile data of GSE17536 and GSE39582 were all generated based on the platform of Affymetrix Human Genome U133 Plus 2.0 Array (GPL570 [HG-U133_Plus_2]). Furthermore, the whole CC-related dataset in TCGA database (https://cancergenome.nih.gov/) were downloaded.

\section{Data preprocessing and DEMs identification}

Normalized RNA-seq data (including 24,991 genes) of TCGA dataset were downloaded for the further investigation. Meanwhile, the CEL source files of GSE17536 and GSE39582 were processed into background adjustment [18], quantile normalization [19], summarization
[20] and Log2 fold change [21] using Robust Multi-array Average (RMA) algorithm [22] in Affy software [23]. Finally, a total of 22,844 and 22,854 genes were obtained from GSE39582 and GSE17536 respectively after data processing.

The DEMs were identified between cancer tissue samples and para-carcinoma tissue samples in TCGA dataset based on Student's t test [24]. P value $<0.05$ and fold change $>2($ or $<1 / 2)$ were defined to be statistically significant.

\section{Functional annotation and pathway enrichment analysis of DEMs}

The Database for Annotation, Visualization and Integrated Discovery (DAVID) [25] is a gene functional classification tool that provides a comprehensive set of functional annotation tools for investigators to understand biological meaning behind large list of genes. By DAVID software, the Gene Ontology (GO, http:// www.geneontology.org) functional annotation [26] and Kyoto Encyclopedia of Genes and Genomes (KEGG) (http://www.genome.jp/kegg/pathway.html) [27] pathway analyses were performed on DEMs in TCGA dataset. $\mathrm{P}<0.05$ was chosen as the cut-off criterion for the enrichment analysis. The results of GO function and KEGG pathway analysis were visualized by ErichmentMap [28] software.

\section{Clinical prognostic analysis}

Based on the DEMs obtained in TCGA dataset, the clinical prognostic analyses including overall survival (OS) and disease-free survival (DFS) analysis were performed on the datasets which have clinical prognostic information. All the three datasets including TCGA, GSE17536 and GSE39582 were used for the overall survival analysis in the present study. Meanwhile, two datasets including GSE17536 and GSE39582 were used for the disease-free survival analysis. The mRNAs in all datasets were divided into high expression group (H group) and low expression group (L group) according to the mean value of DEMs. The survival estimation and survival curve examination were performed using Kaplan-Meier method [29] and log-rank test [30], respectively. The hazard ratio (HR) was estimated with the single variable Cox proportional risk regression model [31]. The independent analysis of prognostic factor was performed based on multivariable Cox proportional risk regression model [32]. Based on the Cox proportional risk regression model, the outstanding DEMs of the single variable in each dataset were considered as the corrected variables. $\mathrm{P}<0.05$ was considered statistically significant. 


\section{Results}

\section{DEMs investigation}

With $\mathrm{P}$ value $<0.05$ and fold change $>2($ or $<1 / 2)$, a total of 954 DEMs including 633 up- and 321 down-regulated mRNA were revealed in TCGA dataset (Fig. 1).

\section{Function annotation and pathway enrichment investigation}

With $\mathrm{P}<0.05$, the GO function and KEGG pathway of DEMs were investigated, followed by visualized using ErichmentMap software. As showed in Fig. 2a, extracellular matrix (GO:0031012), chromatin assembly or disassembly (GO:0006333) and endopeptidase activity (GO:0004175) were outstanding functions assembled with up-regulated DEMs. Meanwhile, the Systemic lupus erythematosus (hsa05322) and Wnt signaling pathway (hsa04310) were two outstanding pathways enriched by up-regulated DEMs (Fig. 2a).

As showed in Fig. 2b, Microsome (GO:0005792), Vesicular fraction (GO:0042598) and Digestion (GO: 0007586) were outstanding functions assembled with the downregulated DEMs, while the Drug metabolism (hsa00983), Androgen and estrogen metabolism (hsa00150, Genes) and Retinol metabolism (hsa00830) were outstanding pathways enriched by down-regulated DMEs (Fig. 2b).

\section{Investigation of CC associated OS prognostic genes}

The relationship between DMEs and OS in each dataset was showed in Fig. 3. The results showed that UL16binding protein 2 (ULBP2) was the outstanding gene in all three dataset including TCGA [Log-rank P 0.0030, HR: 0.552, 95\% confidence interval (CI) 0.37-0.82], GSE17536 (Log-rank P 0.0005, HR: 0.380, 95\% CI 0.220.67 ) and GSE39582 (Log-rank P 0.0092, HR: 0.685, 95\% CI 0.51-0.91). Furthermore, up-regulation of $U L B P 2$ gene was associated with shorter OS of $C C$ patients. The detail information was showed in Fig. 4.

\section{Investigation of DFS prognostic gene}

The relationship between DMEs and DFS prognostic genes associated with $\mathrm{CC}$ in each dataset was showed in Fig. 5. The results showed that a total of 12 DEMs were outstanding in both GSE17536 and GSE39582, including Surfactant Associated 2 (SFTA2), LEM Domain Containing 1 ( $L E M D 1)$, Cartilage Oligomeric Matrix Protein $(C O M P)$, Kinesin Family Member 26B (KIF26B), Kallikrein Related Peptidase 10 (KLK10), Matrix Metallopeptidase 11 (MMP11), Gastrin Releasing Peptide (GRP), Twist Family BHLH Transcription Factor 1 (TWIST1), Regulator Of G Protein Signaling 16 (RGS16), Collagen Type VIII Alpha 1 Chain (COL8A1), Transmembrane Protein 37 (TMEM37), Rho GTPase Activating Protein 44 (ARHGAP44) (Table 1). Notably, the relation between

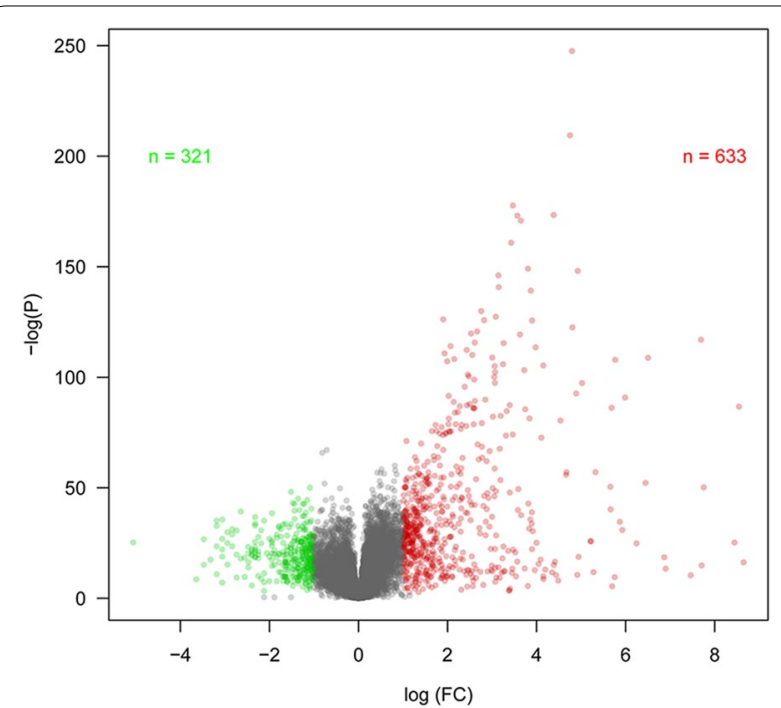

Fig. 1 Volcano plot showing differentially expressed mRNAs. The $X$-axis represents the log fold-change $(F C)$ values; the $Y$-axis represents the- $\log P$ values; green point represents the down-regulated mRNAs; the red point represents the up-regulated mRNAs; those points having a FC larger than 2 (or FC $<1 / 2$ ) are shown in gray

up-regulation of SFTA2 and short DFS in CC patients was showed in Fig. 6.

\section{Independent DFS prognostic genes analysis}

The independent DFS prognostic genes in CC were explored in GSE17536 and GSE39582. The results showed that GRP and TMEM37 were outstanding in totally 12 DEMs after the multivariate Cox proportional risk regression (Table 2 ).

\section{Conclusion}

In sum, ULBP2 might be a potential novel OS prognostic biomarker in CC, while GRP and TMEM37 could be served as the independent DFS prognostic genes in $C C$. Furthermore, functions including extracellular matrix and digestion, as well as pathways including Wnt signaling and drug metabolism may play important roles in the process of CC.

\section{Discussion}

The current informatics study revealed the potential independent prognostic genes for survival of $\mathrm{CC}$, as well as the molecular mechanism during $\mathrm{CC}$ process. A total of 633 up- and 321 down-regulated DEMs were revealed between cancer tissue samples and para-carcinoma tissue samples. The up-regulated mRNAs were mainly assembled in functions including Extracellular matrix and pathways including Wnt signaling. The down-regulated mRNAs were mainly assembled in functions like 


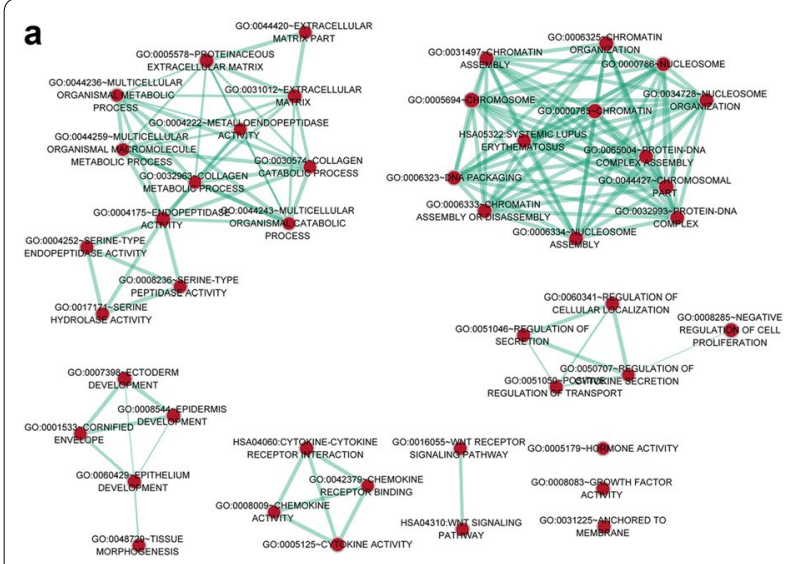

b
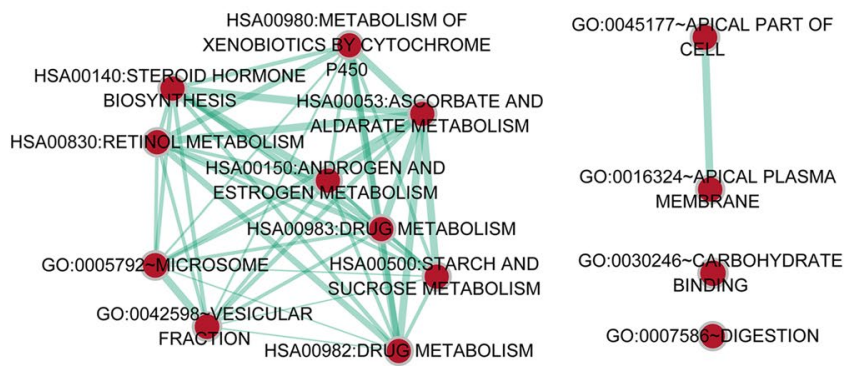

Fig. 2 The GO function and KEGG pathways enrichment analysis for the up- and down-regulated mRNAs. a the network constructed by the up-regulated mRNAs; b the network constructed by the down-regulated mRNAs; GO represents Gene Ontology; KEGG represents Kyoto Encyclopedia of Genes and Genomes; the red point represents a certain name of GO function or KEGG pathway; the green line represents the interaction between two points; the thickness of the line indicates the number of overlapping genes between the different gene sets
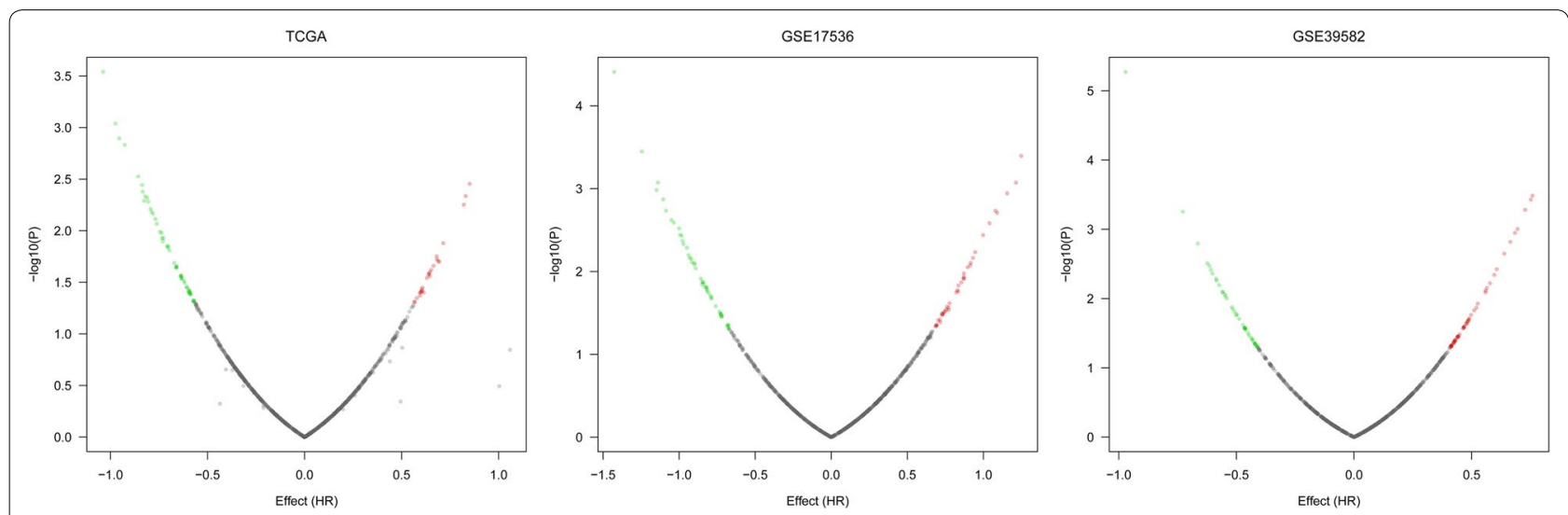

Fig. 3 Cox proportional risk regression plot analyses between differentially expressed microRNAs and overall survival in colon cancer. X-axis represents the logarithm of hazard ratio (HR), the positive expression is associated with better prognosis, and negative expression of gene expression is associated with poor prognosis; $Y$-axis represents logarithm of $P$ value for the log-rank test
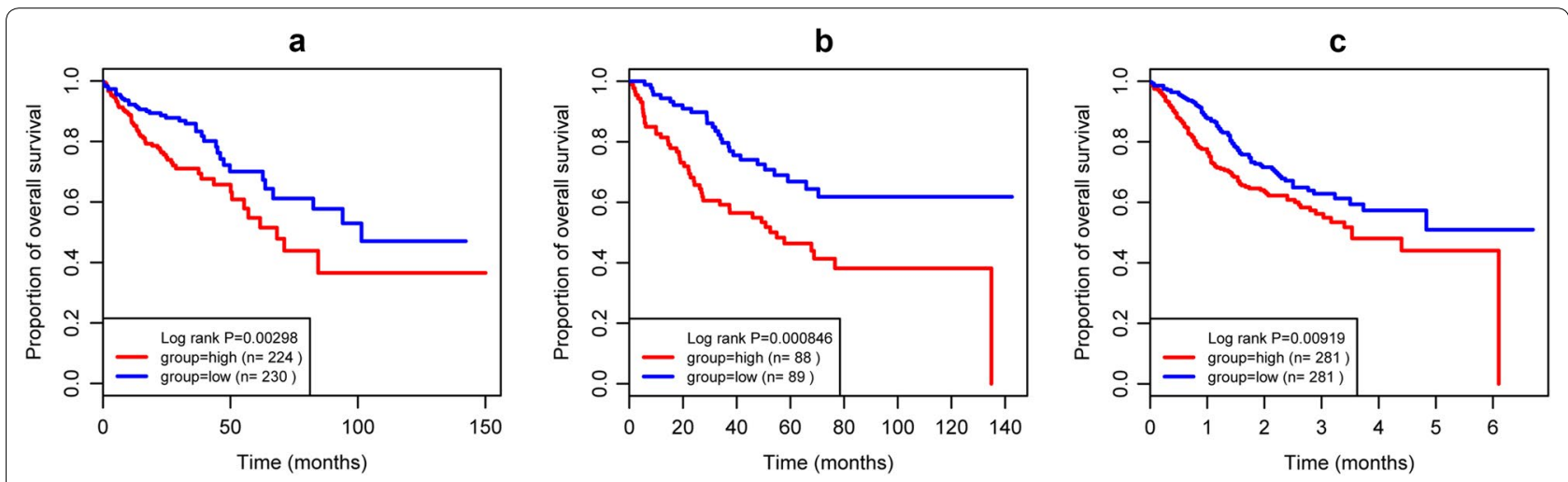

Fig. 4 Kaplan-Meier analyses for the relation between shorter overall survival and UL16 Binding Protein 2 gene in colon cancer. a The TCGA dataset; b the GSE17536 dataset; $\mathbf{c}$ the GSE39582 dataset 

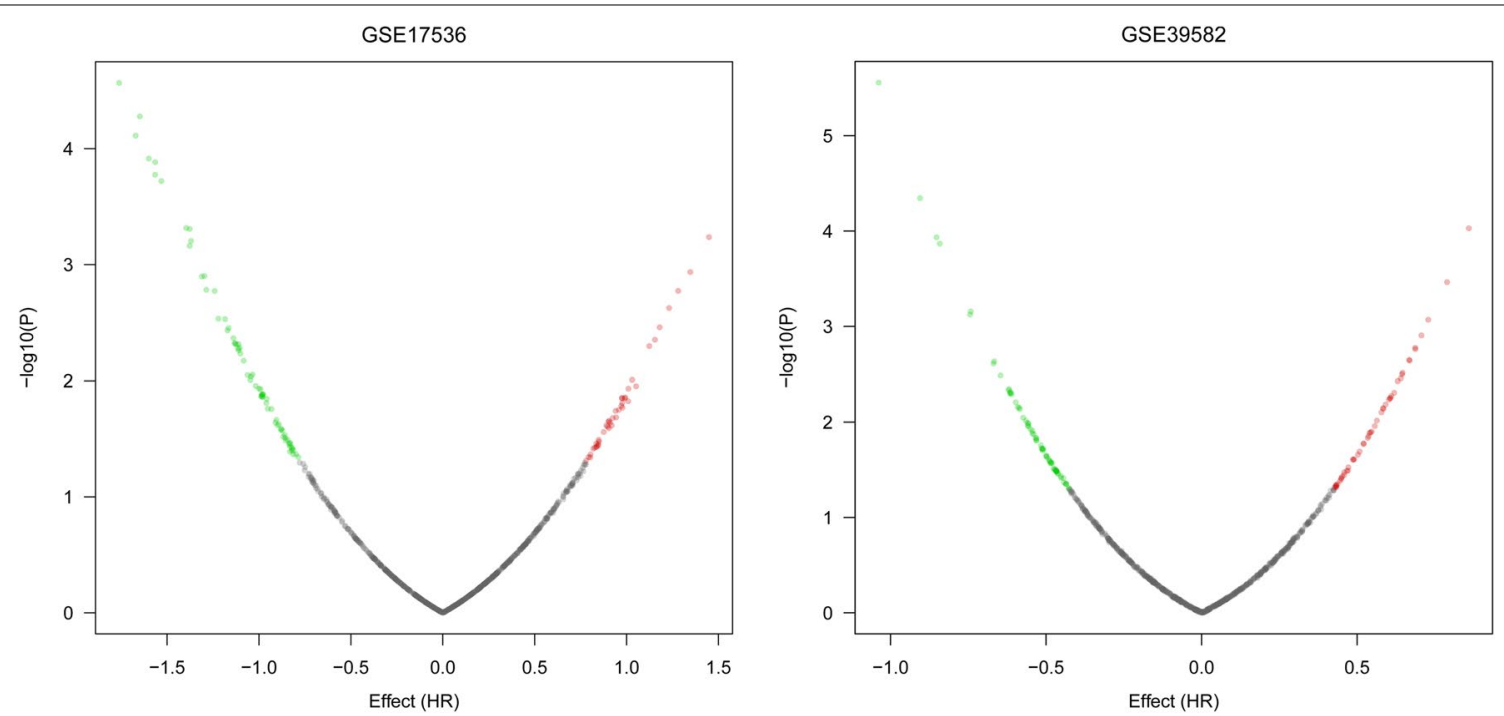

Fig. 5 Cox proportional risk regression plot analyses between differentially expressed microRNAs and disease-free survival in colon cancer. X-axis represents the logarithm of hazard ratio (HR), the positive expression is associated with better prognosis, and negative expression of gene expression is associated with poor prognosis; $Y$-axis represents logarithm of $P$ value for the log-rank test

Table 1 The outstanding disease-free prognostic genes for colon cancer

\begin{tabular}{|c|c|c|c|c|c|c|c|c|}
\hline \multirow[t]{2}{*}{ Gene } & \multirow[t]{2}{*}{$\mathrm{FC}$} & \multirow[t]{2}{*}{$P$} & \multicolumn{3}{|l|}{ GSE17536 } & \multicolumn{3}{|l|}{ GSE39582 } \\
\hline & & & Log-rank P & $H R$ & $95 \% \mathrm{Cl}$ & Log-rank P & $H R$ & $95 \% \mathrm{Cl}$ \\
\hline SFTA2 & 63.45 & $1.6 \mathrm{E}-91$ & 8.87E-03 & 0.488 & $0.49(0.28-0.84)$ & $2.29 \mathrm{E}-02$ & 0.708 & $0.71(0.53-0.95)$ \\
\hline LEMD1 & 32.47 & $4.3 E-98$ & $1.32 \mathrm{E}-02$ & 0.506 & $0.51(0.29-0.88)$ & 1.47E-02 & 0.692 & $0.69(0.51-0.93)$ \\
\hline COMP & 14.33 & $4.3 \mathrm{E}-82$ & $3.70 \mathrm{E}-03$ & 0.444 & $0.44(0.25-0.78)$ & $1.48 \mathrm{E}-02$ & 0.691 & $0.69(0.51-0.93)$ \\
\hline KIF26B & 6.86 & $2.4 \mathrm{E}-64$ & $5.85 \mathrm{E}-03$ & 0.466 & $0.47(0.27-0.81)$ & $1.09 \mathrm{E}-02$ & 0.679 & $0.68(0.5-0.92)$ \\
\hline KLK10 & 6.06 & $1.1 \mathrm{E}-99$ & $5.28 \mathrm{E}-03$ & 0.462 & $0.46(0.26-0.81)$ & 7.06E-03 & 0.666 & $0.67(0.49-0.9)$ \\
\hline MMP11 & 3.74 & $6.8 \mathrm{E}-127$ & $2.96 \mathrm{E}-03$ & 0.44 & $0.44(0.25-0.77)$ & $3.68 \mathrm{E}-02$ & 0.731 & $0.73(0.54-0.98)$ \\
\hline GRP & 3.22 & $2.4 \mathrm{E}-15$ & $1.43 \mathrm{E}-02$ & 0.515 & $0.52(0.3-0.88)$ & $1.16 \mathrm{E}-04$ & 0.554 & $0.55(0.41-0.75)$ \\
\hline TWIST1 & 2.59 & $1.3 \mathrm{E}-28$ & 4.07E-02 & 0.562 & $0.56(0.32-0.98)$ & $4.29 E-02$ & 0.736 & $0.74(0.55-0.99)$ \\
\hline RGS16 & 2.29 & $2.1 \mathrm{E}-25$ & $1.90 \mathrm{E}-04$ & 0.346 & $0.35(0.19-0.62)$ & $3.48 \mathrm{E}-02$ & 0.726 & $0.73(0.54-0.98)$ \\
\hline COL8A1 & 2.01 & $9.6 \mathrm{E}-15$ & $1.68 \mathrm{E}-04$ & 0.338 & $0.34(0.19-0.61)$ & $6.21 \mathrm{E}-03$ & 0.661 & $0.66(0.49-0.89)$ \\
\hline TMEM37 & 0.47 & $1.3 E-23$ & $1.41 \mathrm{E}-02$ & 1.986 & $1.99(1.14-3.47)$ & $1.28 \mathrm{E}-02$ & 1.457 & $1.46(1.08-1.96)$ \\
\hline ARHGAP44 & 0.45 & $4.8 \mathrm{E}-20$ & $4.88 \mathrm{E}-02$ & 1.717 & $1.72(1-2.96)$ & $4.58 \mathrm{E}-02$ & 1.349 & $1.35(1-1.82)$ \\
\hline
\end{tabular}

FC fold change, $H R$ hazard ratio, $\mathrm{Cl}$ confidence interval

$\mathrm{P}<0.05$ was considered as significant different

Digestion and pathways like Drug metabolism. Furthermore, up-regulation of $U L B P 2$ was associated with OS in CC patients. A total of 12 genes including SFTA2 were potential DFS prognostic genes in CC patients. Meanwhile, the GRP and TMEM37 were two outstanding independent DFS prognostic genes in CC.

The extracellular matrix is a collection of extracellular molecules secreted by cells that provides structural and biochemical support to the surrounding cells [33]. Extracellular matrix plays an important role in cancer progression as a dynamic niche [34]. A previous study shows that matrix metalloproteinase- 9 is an important marker for analysis of the postoperative prognosis and risk of metastases in patients with colorectal cancer [35]. Recently, Wang et al. showed that the extracellular matrix protein mindin attenuated colon cancer progression by blocking angiogenesis via Egr-1-mediated regulation [36]. Despite of extracellular matrix, the digestion function is closed related to cancer preventative activity [37]. The microflora in digestion system degrades a wide variety of organic compounds including food additives, drugs, bile salts and cholesterol which may be relevant 
a

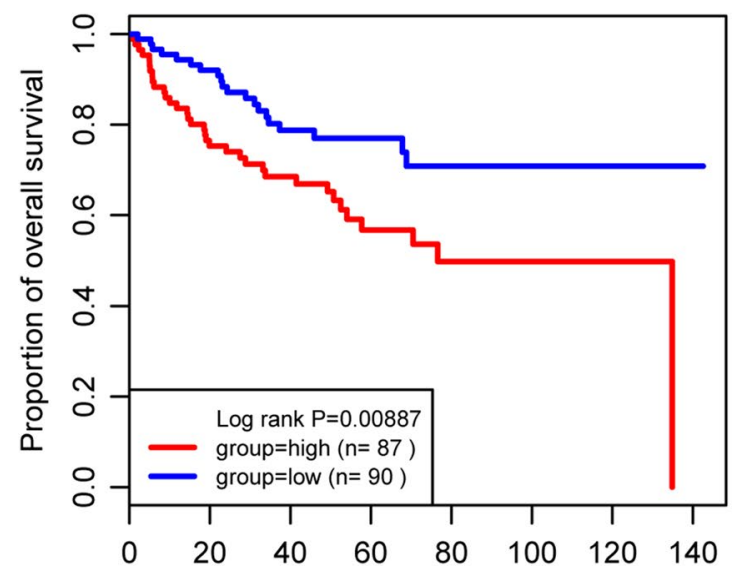

b

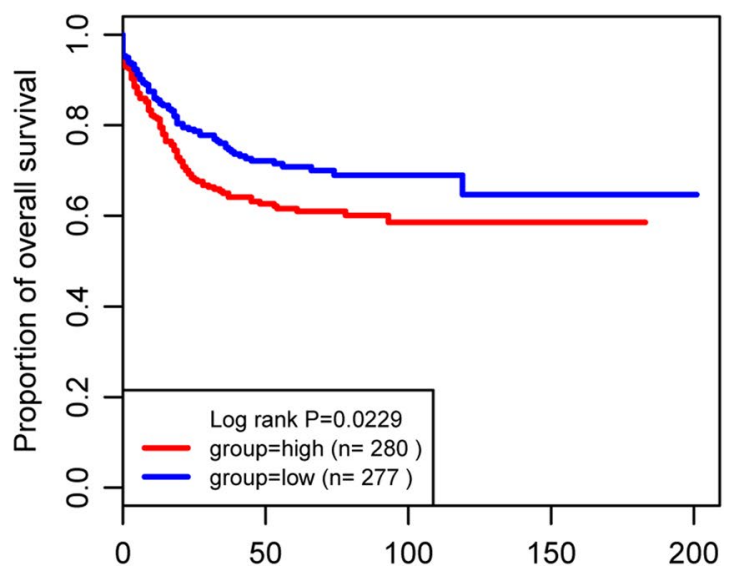

Fig. 6 Kaplan-Meier analyses for the relation between shorter disease-free survival and Surfactant Associated 2 gene in colon cancer. a The GSE17536 dataset; b the GSE39582 dataset

Table 2 The potential disease-free survival independent prognostic gene for colon cancer

\begin{tabular}{|c|c|c|c|c|c|c|}
\hline \multirow[t]{2}{*}{ Gene } & \multicolumn{3}{|c|}{ GSE17536 } & \multicolumn{3}{|c|}{ GSE39582 } \\
\hline & $P$ & HR & HRse & $\mathbf{P}$ & $H R$ & HRse \\
\hline SFTA2 & 0.07 & 0.542 & $0.28-1.051$ & 0.114 & 0.775 & $0.565-1.063$ \\
\hline LEMD1 & 0.465 & 0.789 & $0.417-1.491$ & 0.156 & 0.796 & $0.581-1.091$ \\
\hline COMP & 0.871 & 0.943 & $0.466-1.91$ & 0.953 & 0.988 & $0.658-1.483$ \\
\hline KIF26B & 0.915 & 1.042 & $0.491-2.211$ & 0.808 & 0.955 & $0.656-1.39$ \\
\hline KLK10 & 0.319 & 0.705 & $0.355-1.401$ & 0.364 & 0.861 & $0.623-1.19$ \\
\hline MMP11 & 0.566 & 0.807 & $0.388-1.679$ & 0.498 & 1.148 & $0.77-1.711$ \\
\hline GRP & 0.275 & 0.707 & $0.38-1.317$ & 0.011 & 0.612 & $0.418-0.895$ \\
\hline TWIST1 & 0.215 & 1.706 & $0.734-3.967$ & 0.932 & 1.017 & $0.686-1.509$ \\
\hline RGS16 & 0.184 & 0.613 & $0.298-1.262$ & 0.917 & 0.982 & $0.696-1.385$ \\
\hline COL8A1 & 0.088 & 0.445 & $0.175-1.128$ & 0.467 & 0.856 & $0.563-1.301$ \\
\hline TMEM37 & 0.012 & 2.177 & $1.183-4.007$ & 0.114 & 1.289 & $0.941-1.766$ \\
\hline ARHGAP44 & 0.931 & 0.973 & $0.524-1.807$ & 0.642 & 1.08 & $0.782-1.49$ \\
\hline
\end{tabular}

HR hazard ratio, HRse hazard ratio standard error

$\mathrm{P}<0.05$ was considered as significant different

to the development of CC [38]. A previous study shows that peptides derived from in vitro gastrointestinal digestion can inhibit human colon cancer cells proliferation and inflammation [39]. In the present study, GO function analysis showed that the up- and down-regulated mRNAs were mainly assembled in extracellular matrix and digestion. Thus, our results reveal that the abnormal of extracellular matrix and digestion function may play vital roles in the progression of CC.

Furthermore, the clinical importance of Wnt signaling pathway has been demonstrated in various diseases including colorectal cancer [40]. A previous study shows that alteration in the Wnt signaling pathway is frequently observed in colorectal cancer with microsatellite instability [41]. Inhibiting the Wnt signaling pathway may be a fruitful strategy for targeting chemotherapy-resistant CC cells [42]. Moreover, drug metabolism is the metabolic breakdown of drugs by living organisms [43]. Landmann indicated that drug metabolism determined resistance of colorectal cancer to resorcinol-based heat shock protein 90 inhibitors [44]. In the present study, Wnt signaling and drug metabolism were two outstanding pathways 
enriched by the up- and down-regulated mRNAs. Thus, we speculate that the DEMs may take part in the CC process via Wnt signaling and drug metabolism.

Prognostic biomarkers for cancer have the power to change the course of a disease if they add value beyond knew prognostic factors [45]. ULBP2, which located on the chromosome 6 , is a gene that encoding the cell surface glycoprotein [46]. A previous study shows that $U L B P 2$ is a novel prognostic biomarker for CC [47]. Demirkol et al. indicated that $U L B P 2$ was a mRNA based stage-independent prognostic marker to prognosticate CC in vivo [48]. In the analysis of pancreatic cancer, researchers have proved that a high level of soluble ULBP2 is deemed an independent indicator for OS [49]. In this study, ULBP2 was identified as the unique mRNA outstanding in all three datasets. Thus, we speculate that $U L B P 2$ may be used as the OS prognostic biomarker in CC. Furthermore, GRP is a regulatory molecule that has been implicated in a number of physiological and pathophysiological processes [50]. A Previous study shows that GRP can better predict the prognosis of patients with colorectal cancer and distant metastasis, and has good sensitivity and specificity [51]. Matkowskyj et al. confirmed that GRP and its receptor's co-expression had the function of differentiation, with highest levels observed in well-differentiated CC cells [52]. Moreover, the transmembrane protein is a type of integral membrane protein that spans the entirety of the biological membrane to which it is permanently attached [53]. Based on the results of previous studies, various transmembrane proteins such as MutL Homolog 1 (MLH1) and Bone Marrow Stromal Cell Antigen 2 (BST2) are associated with the progression of $C C[54,55]$. Unfortunately, there is no related study based on transmembrane protein TMEM37 and CC. In the current study, independent DFS prognostic genes analysis showed that GRP and TMEM37 were two most outstanding mRNAs, which might be used as the independent DFS prognostic genes. However, a further clinical investigation based on a large scale of sample size is still needed to confirm the thesis speculation.

\section{Highlights}

1. ULBP2 was a novel overall survival prognostic gene in CC.

2. GRP was an independent disease-free survival prognostic gene in CC.

3. TMEM37 was an independent disease-free survival prognostic gene in CC.

4. Extracellular matrix and digestion functions were important for CC.

5. Wnt signaling and drug metabolism pathways were vital for CC.

\section{Abbreviations}

CC: colon cancer; TCGA: The Cancer Genome Atlas; OS: overall survival; DFS: disease-free survival.

\section{Authors' contributions}

ZS carried out the Conception and design of the research, participated in the Acquisition of data and drafted the manuscript. YZ carried out the Analysis and interpretation of data. WY participated in the design of the study and performed the statistical analysis. CL conceived of the study, and participated in its design and coordination and helped to draft the manuscript. All authors read and approved the final manuscript.

\section{Author details \\ ${ }^{1}$ Gastrointestinal Colorectal and Anal surgery, China-Japan Union Hospital of Jilin University, No. 126 Xiantai Street, Changchun, Jilin 130033, China. \\ ${ }^{2}$ Department of Neurology, The First Hospital of Jilin University, Changchun, Jilin 130021, China.}

\section{Acknowledgements}

Not applicable.

\section{Competing interests}

The authors declare that they have no competing interests.

\section{Availability of data and materials}

Not applicable. This study was only the primary research, and further study has been in progress.

Consent for publication

Not applicable.

\section{Ethics approval and consent to participate}

This study was approved by Ethics Committee of China-Japan Union Hospital of Jilin University and The First Hospital of Jilin University.

\section{Funding}

None

\section{Publisher's Note}

Springer Nature remains neutral with regard to jurisdictional claims in published maps and institutional affiliations.

Received: 8 January 2018 Accepted: 29 March 2018

Published online: 13 April 2018

\section{References}

1. O'Brien CA, Pollett A, Gallinger S, Dick JE. A human colon cancer cell capable of initiating tumour growth in immunodeficient mice. Nature. 2007;445(7123):106.

2. Stewart BW, Kleihues P. World cancer report. World cancer report, vol. 45. Lyon: IARCPress; 2014. p. 12-351.

3. Peto R, Lopez AD, Pan H, Thun MJ. World cancer report. Lyon: IARCPress; 2014

4. Dlamini Z, Khoza T, Hull R, Choene M, Mkhize-Kwitshana Z. Current immunotherapeutic treatments in colon cancer. Rijeka: Intech; 2016.

5. Dienstmann R, Salazar R, Tabernero J. Personalizing colon cancer adjuvant therapy: selecting optimal treatments for individual patients. J Clin Oncol Off J Am Soc Clin Oncol. 2015;33(16):1787.

6. Abdalla M, Landerholm K, Andersson P, Andersson RE, Myrelid P. Risk of rectal cancer after colectomy for patients with ulcerative colitis-a national cohort study. Clin Gastroenterol Hepatol Off Clin Pract J Am Gastroenterol Assoc. 2016;15:1055-60.

7. Grady WM, Markowitz SD. Genetic and epigenetic alterations in colon cancer. Annu Rev Genomics Hum Genet. 2002;3(3):101-28. 
8. Zhang J, Pan M. Genetic or non-genetic prognostic factors in colon cancer. In: International conference on fuzzy systems and knowledge discovery: 2016; 2016. p. 1146-50.

9. Vishnubalaji R, Hamam R, Abdulla MH, Mohammed MAV, Kassem M, Alobeed O, Aldahmash A, Alajez NM. Genome-wide mRNA and miRNA expression profiling reveal multiple regulatory networks in colorectal cancer. Cell Death Dis. 2015;6(1):e1614

10. Amirkhah R, Schmitz U, Linnebacher M, Wolkenhauer O, Farazmand A. MicroRNA-mRNA interactions in colorectal cancer and their role in tumor progression. Genes Chromosom Cancer. 2015;54(3):129-41.

11. Olsen J, Kirkeby LT, Olsen J, Eiholm S, Jess P, Gögenur I, Troelsen JT. High interleukin-6 mRNA expression is a predictor of relapse in colon cancer. Anticancer Res. 2015;35(4):2235.

12. Lassmann S, Schuster I, Walch A, Göbel H, Jütting U, Makowiec F, Hopt U, Werner M. STAT3 mRNA and protein expression in colorectal cancer: effects on STAT3-inducible targets linked to cell survival and proliferation. J Clin Pathol. 2007;60(2):173.

13. Nielsen BS, Jørgensen S, Fog JU, Søkilde R, Christensen IJ, Hansen U, Brünner N, Baker A, Møller S, Nielsen HJ. High levels of microRNA-21 in the stroma of colorectal cancers predict short disease-free survival in stage II colon cancer patients. Clin Exp Metas. 2011;28(1):27-38.

14. Alexopoulou DK, Kontos CK, Spyridon C, Papadopoulos IN, Andreas S. KLK11 mRNA expression predicts poor disease-free and overall survival in colorectal adenocarcinoma patients. Biomark Med. 2014;8(5):671-85.

15. Smith JJ, Deane NG, Fei WU, Merchant NB, Zhang B, Jiang A, Pengcheng LU, Johnson JC, Schmidt C, Bailey CE. Experimentally derived metastasis gene expression profile predicts recurrence and death in patients with colon cancer. Gastroenterology. 2010;138(3):958.

16. Freeman TJ, Smith JJ, Chen X, Washington MK, Roland JT, Means AL, Eschrich SA, Yeatman TJ, Deane NG, Beauchamp RD. Smad4-mediated signaling inhibits intestinal neoplasia by inhibiting expression of $\beta$-catenin. Gastroenterology. 2012;142(3):562.

17. Marisa L, De RA, Duval A, Selves J, Gaub MP, Vescovo L, Etiennegrimaldi MC, Schiappa R, Guenot D, Ayadi M. Gene expression classification of colon cancer into molecular subtypes: characterization, validation, and prognostic value. Plos Med. 2013;10(5):e1001453.

18. Wu Z, Irizarry RA, Gentleman R, Martinezmurillo F, Spencer F. A mode based background adjustment for oligonucleotide expression arrays. Johns Hopkins University Dept of Biostatistics Working Paper. 2004; 99(468):909-17.

19. Hu J, He X. Enhanced quantile normalization of microarray data to reduce loss of information in gene expression profiles. Biometrics. 2007;63(1):50-9.

20. Mishra R, Bian J, Fiszman M, Weir CR, Jonnalagadda S, Mostafa J, Fiol GD. Text summarization in the biomedical domain: a systematic review of recent research. J Biomed Inform. 2014;52:457-67.

21. Benoît M, Bernadette $G$, Annie R, Bertrand B, Jérôme A, Jean-Luc G. Impact of the spotted microarray preprocessing method on fold-change compression and variance stability. BMC Bioinform. 2011;12(1):1-12.

22. Irizarry RA, Hobbs B, Collin F, Beazer-Barclay YD, Antonellis KJ, Scherf U, Speed TP. Exploration, normalization, and summaries of high density oligonucleotide array probe level data. Biostatistics. 2003;4(2):249-64.

23. Gautier L, Cope L, Bolstad BM, Irizarry RA. affy-analysis of Affymetrix GeneChip data at the probe level. Bioinformatics. 2004;20(3):307-15.

24. Gooch JW. Student's t. Encyclopedic dictionary of polymers, vol. 81(5). Berlin: Springer; 2011. p. 707.

25. Dennis G Jr, Sherman BT, Hosack DA, Yang J, Gao W, Lane HC, Lempicki RA. DAVID: database for annotation, visualization, and integrated discovery. Genome Biol. 2003;4(5):P3.

26. Harris MA. The gene ontology (GO) database and informatics resource. New York City: WCB/McGraw-Hill; 2004.

27. Arakawa K, Kono N, Yamada Y, Mori H, Tomita M. KEGG-based pathway visualization tool for complex omics data. Silico Biol. 2005;5(4):419-23.

28. Merico D, Isserlin R, Stueker O, Emili A, Bader GD. Enrichment map: a network-based method for gene-set enrichment visualization and interpretation. PLoS ONE. 2010:5(11):e13984.

29. Bland JM, Altman DG. Survival probabilities (the Kaplan-Meier method). BMJ. 1998:317(7172):1572.

30. Alberti C, Timsit JF, Chevret S. Survival analysis - the log rank test. Rev Mal Respir. 2005;22(5 Pt 1):829-32
31. Persson I. Bias of the cox model hazard ratio. J Mod Appl Stat Methods Jmasm. 2005;4(1):90-9.

32. He J, Xiao L, Tan J, Dai Z, Wang Q, Surgery DO. The risk factors analysis of prognosis of patients with intracerebral hemorrhage by Cox proportional hazard regression model. Chin J Pract Neruous Dis. 2015;2:1-3.

33. Michel GT, Tonon T, Scornet D, Cock JM, Kloareg B. The cell wall polysaccharide metabolism of the brown alga Ectocarpus siliculosus. Insights into the evolution of extracellular matrix polysaccharides in Eukaryotes. New Phytol. 2010;188(1):82-97.

34. Lu P, Weaver VM, Werb Z. The extracellular matrix: a dynamic niche in cancer progression. J Cell Biol. 2012;196(4):395-406.

35. Golovkov DA. Key enzymes of the extracellular matrix in colorectal cancer. Bull Exp Biol Med. 2009;147(3):353.

36. Wang LF, Liu YS, Yang B, Li P, Cheng XS, Xiao CX, Liu JJ, Li S, Ren JL, Guleng $B$. The extracellular matrix protein mindin attenuates colon cancer progression by blocking angiogenesis via Egr-1-mediated regulation. Oncogene. 2017;37:601 (Epub ahead of print).

37. Ferruzzi MG, Blakeslee J. Digestion, absorption, and cancer preventative activity of dietary chlorophyll derivatives. Nutr Res. 2007;27(1):1-12.

38. Cummings JG. The colon: absorptive, seccretory and metabolic functions. Digestion. 1975;13(4):232-40.

39. González-Montoya M, Hernández-Ledesma B, Silván JM, Mora-Escobedo R, Martínez-Villaluenga C. Peptides derived from in vitro gastrointestinal digestion of germinated soybean proteins inhibit human colon cancer cells proliferation and inflammation. Food Chem. 2017;242:75-82.

40. Godman CA, Joshi R, Tierney BR, Greenspan E, Rasmussen TP, Wang H, Shin DG, Rosenberg DW, Giardina C. HDAC3 impacts multiple oncogenic pathways in colon cancer cells with effects on Wnt and vitamin D signaling. Cancer Biol Ther. 2008;7(10):1570-80.

41. Shimizu Y, Ikeda S, Fujimori M, Kodama S, Nakahara M, Okajima M, Asahara T. Frequent alterations in the Wnt signaling pathway in colorectal cancer with microsatellite instability. Genes Chromosom Cancer. 2002;33(1):73-81.

42. Chikazawa N, Tanaka H, Tasaka T, Nakamura M, Tanaka M, Onishi H, Katano M. Inhibition of Wnt signaling pathway decreases chemotherapy-resistant side-population colon cancer cells. Anticancer Res. 2010;30(6):2041-8.

43. Wilkinson GR. Drug metabolism and variability among patients in drug response. N Engl J Med. 2005;352(21):2211-21.

44. Landmann $\mathrm{H}$. Drug metabolism determines resistance of colorectal cancer to resorcinol-based HSP90 inhibitors. Göttingen: University Library Göttingen; 2014.

45. Guo Z, Shu Y, Zhou H, Zhang W. Identification of diagnostic and prognostic biomarkers for cancer: focusing on genetic variations in microRNA regulatory pathways (Review). Mol Med Rep. 2016;13(3):1943-52.

46. Radosavljevic M, Cuillerier B, Wilson MJ, Clément O, Wicker S, Gilfillan S, Beck S, Trowsdale J, Bahram S. A cluster of ten novel MHC class I related genes on human chromosome 6q24.2-q25.3. Genomics. 2002;79(1):114-23.

47. Gomceli I. A combined ULBP2 and SEMA5A expression signature as a prognostic and predictive biomarker for colon cancer. J Cancer. 2017;8(7):1113-22.

48. Demirkol S, Gomceli I, Isbilen M, Dayanc BE, Tez M, Bostanci EB, Akoglu M, Ozyerli E, Durdu S, Konu O. Expression of SEMA5A and ULBP2 are predictors of prognosis and chemosensitivity in colon cancer. In: International symposium on abdominal metastatic cancer: 2015; 2015.

49. Chen J, Zhu XX, Xu H, Fang HZ, Zhao JQ. Expression and prognostic significance of unique ULBPs in pancreatic cancer. Oncotargets Ther. 2016:9:5271.

50. Pansky A, Weerth AD, Fasler-Kan E, Boulay JL, Schulz M, Ketterer S, Selck C, Beglinger C, Schrenck TV, Hildebrand P. Gastrin releasing peptide. J Am Soc Nephrol Jasn. 2000;11(8):1409-18.

51. Liao JT, Li Y, Chen YY. Gastrin-releasing peptide and its receptors expression in colorectal cancer. Guide China Med. 2015;30:7-10.

52. Matkowskyj KA, Keller K, Glover S, Kornberg L, Transontay R, Benya RV. Expression of GRP and its receptor in well-differentiated colon cancer cells correlates with the presence of focal adhesion kinase phosphorylated at tyrosines 397 and 407. J Histochem Cytochem Off J Histochem Soc. 2003;51(8):1041. 
53. Almén MS, Nordström KJ, Fredriksson R, Schiöth HB. Mapping the human membrane proteome: a majority of the human membrane proteins can be classified according to function and evolutionary origin. BMC Biol. 2009:7(1):50.

54. Mukai S, Oue N, Oshima T, Mukai R, Tatsumoto Y, Sakamoto N, Sentani K, Tanabe K, Egi H, Hinoi T. Overexpression of transmembrane protein BST2 is associated with poor survival of patients with esophageal, gastric, or colorectal cancer. Ann Surg Oncol. 2017;24(2):1-9.

55. Hepzibah W, John William S, Balaji M. Molecular modeling and identification of transmembrane protein (MLH1) related to colon cancer using Insilico techniques. Int J Novel Trends Pharm Sci. 2016;6(3):3.
Ready to submit your research? Choose BMC and benefit from:

- fast, convenient online submission

- thorough peer review by experienced researchers in your field

- rapid publication on acceptance

- support for research data, including large and complex data types

- gold Open Access which fosters wider collaboration and increased citations

- maximum visibility for your research: over $100 \mathrm{M}$ website views per year

At BMC, research is always in progress.

Learn more biomedcentral.com/submissions 